\title{
Unit roots in macroeconomic time series: theory, implications, and evidence
}

Gilberto A. Libanio Assistant Professor at Federal University of Minas Gerais (Brazil) and Doctoral Candidate in Economics at the University of Notre Dame (USA)

\section{Key words}

time-series models, unit roots, business fluctuations.

JEL Classification C22, E32.

\author{
Palauras-chave \\ modelos de séries temporais, raizes \\ unitárias. flutuações econômicas.
}

Classificação JEL C22, E32.

\section{Abstract}

The theme of unit roots in macroeconomic time series has received a great amount of theoretical and applied research in the last two decades. This paper presents some of the main issues regarding unit root tests, explores some of the implications for macroeconomic theory and policy, and reviews the recent evidence on the presence of unit roots in GDP series for Latin American countries. We conclude that a consensual view on many of the aspects involved has not emerged from this literature.

\section{Resumo}

A existência de raizes unitárias em series temporais macroeconômicas tem sido objeto de extensa pesquisa teórica e empírica nas últimas duas décadas. O presente artigo discute algumas das principais questões relacionadas a testes de raizes unitárias, explora algumas implicacõos para teoria e politica macroeconômica, e apresenta a evidencia recente sobre a existência de raizes unitárias em séries de PIB em países da América Latina. O artigo conclui que não se formon um consenso a respeito de várias das questões envolvidas nesse debate. 


\section{1_Introduction}

It has been two decades since the influential work by Nelson and Plosser (1982) on the existence of unit roots in macroeconomic time series was published. Their 1982 paper is usually recognized as an important contribution with repercussions for theory and policy, and as the starting point of a large literature in macroeconomics and econometrics.

Nelson and Plosser's main achievement is to present statistical evidence that supports the hypothesis of a unit root in the autoregressive representations of a dozen macroeconomic time series for the US, including GNP, employment, wages, prices, interest rates, and stock prices. As I will discuss in the following sections, these results have significant implications for econometric modeling, for business cycle theorizing, and for economic policy prescriptions.

The presence or absence of unit roots, to put it simply, helps to identify some features of the underlying data-generating process of a series. If a series has no unit roots, it is characterized as stationary, and therefore exhibits mean reversion in that it fluctuates around a constant long run mean. Also, the absence of unit roots implies that the series has a finite variance which does not depend on time (this point is crucial for economic forecasting), and that the effects of shocks dissipate over time.

Alternatively, if the series feature a unit root, they are better characterized as non-stationary processes that have no tendency to return to a long-run deterministic path. Besides, the variance of the series is time-dependent and goes to infinity as time approaches infinity, which results in serious problems for forecasting. Finally, non-stationary series suffer permanent effects from random shocks. As usually denominated in the literature, series with unit roots follow a random walk.

In sum, the existence (or lack thereof) of unit roots in macroeconomic time series brings about important implications, and this helps to explain why this topic has received a great amount of theoretical and applied research in the last two decades. There are many different issues in the unit roots literature that are somehow related but can be explored separately. To the question "why do we care about unit roots in GNP?" Cribari-Neto (1996, p. 38) provides the following answer: 
To a policymaker the answer could be:

'Because the policy implications are different.' To a macroeconomist, it could be answered that 'there are theoretical implications on several theories and models.' Finally, an econometrician would be satisfied with the answer: 'Because the asymptotics are different.'

This paper presents some of the main issues regarding unit root tests, explores some of the implications for macroeconomic theory and policy, and reviews the recent evidence on the presence of unit roots in GDP series for Latin American countries. The remainder of the paper is organized as follows. The next section considers the major contributions in the literature on unit root testing (with a focus on aggregate output series), since the work of Nelson and Plosser (1982). Section 3 discusses implications for business cycle theorizing, including the initial support for real business cycle theories, and the reactions to that perspective. Section 4 presents recent empirical results regarding the existence of unit roots in Latin American GDP series. Finally, the last section summarizes the arguments, explores some economic policy implications, and presents possible directions for future research.

\section{2_ Testing for unit roots in GNP series}

Consider two alternative models used to represent GNP time series:

$y_{t}=a+b_{t}+e_{t}$
$y_{t}=a+y_{t-1}+e_{t}$

where: $y_{t}$ represents the natural logarithm of GNP at time $t$; $t$ represents a time trend; $b$ is a constant that gives the growth rate of the variable; $e$ is an error term with zero mean and finite variance.

The first specification implies that GNP equals the constant $a$ at time zero $\left(y_{0}=a\right)$ and grows over time at a constant rate $b$, with the error term explaining deviations from the trend in each year. In other words, the variable $y_{t}$ presents a stationary fluctuation around the time trend $a+b t$. Therefore, the variable is described as trend stationary (TS), and stationarity is achieved by removing the time trend ("detrending"), i. e. regressing $y_{t}$ on $t$. Another feature of model (1) is that the variance of $y_{t}$ is bounded by the variance of $e_{t}$, and the linear forecast of GNP converges to the time trend $a+b t$ as the forecast horizon increases. 
Finally, for the first specification, the effects of a shock at time $t$ tend to zero over time, since the error term affects the outcome in the current period, but has no persistent influence in succeeding time periods.

Model (2), on the other hand, specifies that GNP grows at rate $a$ from its previous value, with an error term playing a role every year. Despite the apparent similitude between the two models, they are indeed very different, and lead to different implications in many respects.

First, model (2) is non-stationary and cannot be made stationary through detrending. But note that the first difference of the series is given by $a+e_{t}$, a stationary process. So, stationarity can be achieved by differencing, and the model is called difference stationary (DS). Model (2) is one of the simplest AR(1) processes, and can be described as a random walk with drift. The dependent variable displays a random fluctuation given by the error term $e_{t}$, in addition to the growth given by the drift term $a$. Contrarily to model (1), however, there is no tendency for $y_{t}$ to return to a predetermined mean value, and its trajectory is given by an accumulation of disturbances. In other words, the error term affects not only what happens in the current period, but also what happens in all succeeding periods. In order to better visualize this point, we can substitute repeatedly for the lagged $y_{t}$ value in equation (2) to get:

$y_{t}=y_{0}+a_{t}+\sum_{i=1}^{t} e_{i}$

It is straightforward to see that the variance of $y_{t}$ grows without bound over time, and that shocks to the system (captured by the error term) have a permanent effect on the series. Also, the mean square error of the forecast of the DS model grows linearly with the forecast horizon.

Model (2) represents the unit root bypothesis, a terminology arising from the fact that the coefficient on $y_{t-1}$ is unity. If this coefficient were less than unity, the series would be stationary (mean reverting) and random shocks would dissipate over time. ${ }^{1}$

In sum, the two models are indeed different and have different implications. Therefore, it is important to check whether a GNP series can be better described as a TS or a DS process. This is usually done by testing for the presence of a unit root in the $\ldots \ldots$

The macroeconomic implications of unit root will be addressed in more detail in section 3 . 
2 Note that under the null hypothesis this t statistic is not asymptotically normally distributed, and therefore special critical values are required. Actually, critical values depend on the regression specification and on the sample size. Dickey and Fuller (1979), among others, provide tables with appropriate critical values for some cases.

3 A complete description of unit root tests is beyond the scope of this article. For an extensive presentation and discussion of unit root tests, see Maddala and Kim (1998). autoregressive representation of the series. If a unit root is found, traditional estimation techniques cannot be used since, as is well known, spurious results are obtained when two variables with unit roots are regressed on each other: misleadingly high $\mathrm{R}$ squares and $t$ statistics, and very low DW statistics.

There are different tests for unit roots described in the literature.

According to Elder and Kennedy (2001, p. 138), "the augmented Dickey-Fuller (ADF) test has become the most popular of many competing tests in the literature". It consists in estimating by OLS a model such as

$y_{t}=a+b t+u y_{t-1}+e_{t}$ in the form

$\Delta y_{t}=(u-1) y_{t-1}+a+b t+e_{t}$

and then testing for $u=1$ (null hypothesis of unit root) using a $t$ test. ${ }^{2}$ Failing to reject the null is equivalent to failing to reject the existence of a unit root or stochastic trend in the data series.

Two major issues in performing ADF tests are the inclusion (or not) of an intercept term, a trend term, or both, and the selection of the truncation lag. ADF test results are very responsive to the presence of intercept and trend terms, and to the number of lags included. In general, including too many deterministic regressors results in lost power, whereas not including enough of them increases the probability of not rejecting the unit-root null. ${ }^{3}$

It is important to note that the way in which classical hypothesis testing is carried out ensures that the null hypothesis is not rejected unless there is strong evidence against it. Since the vast majority of unit root tests have non-stationarity, i. e. a unit root, as the null hypothesis, it is not surprising that unit root tests usually conclude that there is a unit root in the series. This problem is exacerbated by the fact that in general unit root tests have low power. However, it is also possible to design tests for the null hypothesis of stationarity against the alternative of a unit root. Kwiatkowski, Phillips, Schmidt, and Shin (1992) introduce such a test, and do it by choosing a components representation in which the time series under study is written as the sum of a deterministic trend, a random walk, and a stationary error. The null hypothesis of trend stationarity corresponds to the hypothesis that the variance of the random walk equals zero. As one could expect, their results are frequently supportive of the trend stationarity hypothesis, contrary to those of the traditional unit root tests. 


\subsection{The seminal contribution of Nelson and Plosser (1982)}

The work by Nelson and Plosser (1982) is usually considered the starting point of a vast amount of research on unit roots in macroeconomic time series. Their paper uses long historical time series of annual data for 14 variables for the US economy, including measures of output, employment, prices, wages, money stock, and interest rates.

Starting dates range from 1860 to 1909, and all series end in 1970. Nelson and Plosser's goal is to examine whether these time series are better characterized as TS or as DS processes.

In particular, they intend to question the traditional practice of decomposing output series into a secular component (long run deterministic trend) and a cyclical component (stationary short run fluctuations around trend). Nelson and Plosser argue that, if the series is non-stationary (i.e. features a unit root in its autoregressive representation), then the secular component should be modeled as a stochastic process, responsible for any long run non-stationarity observed in the series, since the cyclical component is assumed to be transitory. In other words,

\section{Since cyclical fluctuations are assumed to dissipate over time, any long-run or permanent movement (non-stationarity) is necessarily attributed to the secular component (Nelson and Plosser, 1982, p. 139-140).}

In this case, aggregate output is thought of as consisting of a non-stationary growth component plus a stationary cyclical component, being the total variation in output changes attributed to both components.

Nelson and Plosser (1982) then analyze sample autocorrelations and test for the existence of unit roots in the fourteen long run time series, and find that the null hypothesis of a unit root cannot be rejected at $5 \%$ for most of the series. The only exception is the unemployment rate, which, as Nelson and Plosser recognize it, was on a priori grounds expected to be stationary around a trend with zero slope.

Nelson and Plosser acknowledge that non-rejection of the null hypothesis does not necessarily imply that the null is 'true'. This is particularly important in the case of unit root tests, since such tests usually have low power, i. e. cannot differentiate between unit roots and a TS alternative with an AR root arbitrarily close to unity. However, they 
argue, if the deviations from a linear trend in the series are stationary,

then the tendency to return to the trend line must be so weak as to avoid detection even in samples as long as sixty years to over a century (Nelson and Plosser, 1982, p. 152).

To sum up, Nelson and Plosser conclude that the evidence presented support the DS representation of non-stationarity in economic time series, and that in this case economic fluctuations are better explained by movements in the secular component (caused mainly by real factors, such as changes in tastes and technology) than by the cyclical component. As we will discuss in section 3, this argument leads to the idea that real business cycle models are likely to provide a better explanation for fluctuations in aggregate output than models that see monetary shocks as the main source of the business cycle.

\section{2_ Measuring the persistence of innovations}

One of the most important findings of Nelson and Plosser was that GNP series can be characterized as non-stationary, and therefore suffer long-term effects from random shocks.
A question that follows naturally is: how persistent are the impacts of shocks? In general terms, the answer to this question relates to the relative importance of the random walk secular component vis-à-vis the stationary cyclical component in the series.

Two different measures of persistency were established in the literature. The first one, proposed by Campbell and Mankiw (1987), is known as the cumulative impulse response function. Campbell and Mankiw's starting point is the assumption that if output series are stationary, and therefore mean-reverting, then a current shock should not change one's forecast of output in the long run (say, five to ten years). They model the change in $\log$ GNP as a stationary ARMA process, and calculate the implied impulse response functions for the level of the series, using quarterly real GNP data for the US from 1947 to 1985. Sixteen different ARMA specifications are considered, varying both $\mathrm{AR}(p)$ and MA ( $q$ ) parameters from zero to three. In most of the specifications (13 out of 16), the model impulse responses show an impact between 1.2 and 1.8 percent over the long run forecast of GNP after a 1 percent shock in the variable. 
Campbell and Mankiw's main conclusion from this evidence is that innovations in real GNP have persistent effects. Their results, therefore, extend the evidence provided by Nelson and Plosser (1982) in favor of unit roots in output series. However, Campbell and Mankiw (1987) do not completely accept Nelson and Plosser's interpretation of such evidence in terms of the determinants of the business cycle. In particular, they argue that demand shocks may still play an important role in output fluctuations, and that the finding of persistency in the series is consistent with a substantial cyclical component. We will return to this point in section 3 .

The second measure of persistency found in the literature was proposed by Cochrane (1988). He shows that any series with a unit root can be seen as a combination of a stationary component and a random walk. His measure of persistency is then related to the relative importance of both components. In other words, Cochrane (1988) aims at addressing the question "how big is random walk in GNP?"

Cochrane's measure of persistency, known as variance ratio, is based on the variance of GNP's long differences, and is given by:

$$
V_{k}=\frac{1}{k} \frac{\operatorname{var}\left(y_{t}-y_{t-k}\right)}{\operatorname{var}\left(y_{t}-y_{t-1}\right)}
$$

This measure of persistence ranges from zero to one. It can be shown that $V_{k}$ approaches zero if the series is stationary, and tends to one in case of a random walk. The intuition behind this measure is that if GNP follows a random walk, then the variance of its $k$-differences grows with $k$, whereas this same variance approaches a constant in case of a stationary series. So, in case of stationarity, the value between square brackets tends to a constant, and growing $k$ causes $V_{k}$ to converge to zero; in case of a pure random walk, the ratio of variances grows with $k$, and therefore $V_{k}$ tends to one.

Cochrane (1988) uses annual data between 1869 and 1986 for the log of per capita GNP in the US and finds that the random walk component responds for about one-third of total output variance. It means that annual GNP growth rates contain an important temporary component, and the level of the series always tends to return to a deterministic trend line. In sum,

These results mean that an $A \mathrm{R}(2)$ about a deterministic trend or a 
difference-stationary ARMA process with a very small random walk component is a good in-sample characterization of the behavior of GNP (Cochrane, 1988, p. 916).

\subsection{Testing for unit roots in series with structural breaks}

Another important development in the literature about unit roots in macroeconomic time series is provided by Perron (1989), who presented a model to test for unit roots in the presence of an exogenous break in the series. In this case, the basic assumption is that outlying events can be separated from the noise function and be modeled as one-time changes in the deterministic part of the time series model.

The importance of Perron's work lies in the fact that unit root tests are biased toward non-rejection of the unit root null when there are structural breaks in the series. To see why this is the case, consider a time series with two distinct subperiods, and an abrupt one-time change in the mean value of the variable between the two intervals. Even if each subperiod is stationary around a zero-sloped trend, a trend line fitted through the entire sample will have a negative slope (assuming that the one-time change is negative, like in the 1929 "crash"), causing unit root tests not to reject the null hypothesis.

Indeed, Perron (1989) shows with a Monte Carlo experiment that the coefficient on $y_{t-1}$ in equation (4) becomes concentrated around 1 as the magnitude of the break increases, and concludes that there is a bias toward the non-rejection of the null in the presence of structural breaks.

Perron (1989) develops a formal procedure to test for unit roots allowing for a structural break. Three possibilities are considered by Perron when modeling this break:

i. a change in the level of the series (intercept);

ii. a change in the rate of growth (slope);

iii. a change in both intercept and slope.

In this case, the null hypothesis is that a series is characterized by the presence of a unit root, with a one-time change at time $T b(1<T b<T)$. The alternative is that the series is stationary around a "broken" trend line. More formally, these hypotheses can be expressed as (Enders, 1995): 
$H_{0}: y_{t}=a_{0}+y_{t-1}+\mu_{1} D_{p}+\mu_{2} D_{L}+e_{t}$
$H_{1}: y_{t}=a_{0}+a_{2} t+\mu_{2} D_{L}+\mu_{3} D_{T}+e_{t}$ where:

i. $D_{p}$ represents a pulse dummy variable that allows for a one-time jump in the level of a unit root process, and is such that $D_{p}=1$ if $t=T b+1$ and zero otherwise;

ii. $D_{L}$ is a level dummy variable that gives a one-time change in the intercept of a TS process, or a one-time change in the drift term of a DS process, and is such that $D_{L}=1$ if $t>T b$ and zero otherwise;

iii. $D_{T}$ represents a dummy variable that changes the slope of the deterministic trend line under $H_{1}$, and is such that $D_{T}=t-T b$ for $t>T b$ and zero otherwise.

Perron's testing strategy consists in estimating the regression equation $H_{1}$ and use the residuals to estimate:

$y_{t}=a_{1} y_{t-1}+e_{t}$

The t-statistic for the null hypothesis $a_{1}=1$ is then compared to the critical values provided by Perron (1989).

Perron (1989) applies this methodology to test for the presence of unit roots using the same data as

Nelson and Plosser (1982). He chooses the stock market crash of 1929 as a break point that permanently changed the level of the series. Also, Perron (1989) applies the same test using quarterly postwar real GNP series for the US economy (1947:1 to 1986: III), and includes a one-time change in the slope of the deterministic trend in 1973 due to the oil price shock. Perron's results challenge most of Nelson and Plosser's conclusions. In short, he is able to reject the unit root null in eleven of the series Nelson and Plosser found to be non-stationary, and proposes that such series are better described as stationary around a trend with a structural break in 1929. The quarterly GNP series is also found to be stationary, with a change in the slope of the trend in 1973.

Summing up: Perron's analysis suggests that a deterministic trend with a few discontinuities caused by large and occasional shocks along with stationary cycles is the best characterization of output fluctuations. In this case, it is argued that persistence arises only from large and infrequent shocks, and that the economy returns to a deterministic trend after small and 
4 See the Jul 1992 issue of the Journal of Business and Economic Statistics. frequent shocks. According to Perron (1989, p. 1361),

Most macroeconomic time series are not characterized by the presence of a unit root. Fluctuations are indeed stationary around a deterministic trend function. The only "shocks" which have had persistent effects are the 1929 crash and the 1973 oil price shock.

Perron's work has received some criticism in the literature, based on the fact that the breaking point is exogenously selected. Papers such as Zivot and Andrews (1992) and Banerjee, Lumsdaine, and Stock (1992) argue that this exogenous determination of the breaking points based on observation of the data can be seen as data mining, and introduces a pre-test bias towards the rejection of the null hypothesis. ${ }^{4}$ The intuition behind this argument is that the choice of breaking points based on the observation of data is not consistent with a testing strategy based on a distribution that is supposed to be data independent.

Several attempts have been made to develop a unit root testing procedure under the assumption that the break points are not known a priori, but are, instead, endogenously determined. In this case, events such as the 1929 crash and the first oil shock are not removed from the noise function of the series. The adequate procedure usually involves the specification of a data dependent algorithm to find out whether or not a breaking point is present in the data, and in which period of the sample it is located. Such procedure transforms Perron's unit-root test, which is conditional on a known breakpoint, into an unconditional unit-root test.

The null hypothesis here is a unit-root process with drift that excludes any structural change, and the relevant alternative hypothesis is a trend-stationary process with a possible structural change occurring at an unknown point in time. The selection of the breakpoint is seen as the outcome of an estimation procedure designed to fit the series to a TS representation. The estimation scheme chooses the breakpoint that gives most weight to the TS alternative hypothesis, $i$. e. the one associated with the lowest $t$-statistic of the coefficient of the lagged variable under consideration.

To consider the possibility of a break in the series, three classes of statistics are considered:

i. recursive statistics, which are computed using subsamples 
$t=1, \ldots, k$ for $k=k_{0}, \ldots, T$, where $k_{0}$ is a start-up value and $T$ is the full size of the sample;

ii. rolling statistics, which are computed using a subsample of fixed size, rolling through the sample;

iii. sequential statistics, which are computed using the full sample, but sequentially allowing for a hypothetical break or shift at every point in the sample.

The empirical results using such strategies are not conclusive. Zivot and Andrews (1992) find less evidence against the unit root hypothesis than Perron (1989) does: they revert Perron's conclusions for five of the eleven Nelson and Plosser series for which the unit root hypothesis was rejected. Besides, Zivot and Andrews are not able to reject the null of unit root for the postwar US GNP series. However, their results for some of the series (industrial production, nominal GNP, and real GNP) reinforce Perron's conclusions against the unit root hypothesis, which is rejected even after endogenizing the breakpoint selection.

Banerjee, Lumsdaine, and Stock (1992) also find mixed results. Using postwar data for seven OECD

countries, they are not able to reject the unit root hypothesis for five countries (France, Germany, Italy, United Kingdom, and US). For two other countries, however, the unit root is rejected against the alternative of a stationary broken trend (Canada and Japan).

Another subsequent development in this literature considers the possibility of two endogenous break points in the series. Lumsdaine and Papell (1997) argue that unit-root tests are sensitive to the number of breaks under the alternative hypothesis, and suggest that the long series analyzed by Nelson and Plosser (1982) and others seem to exhibit two breaks. They reexamine the Nelson-Plosser data allowing for two endogenous break points, and find more evidence against the unit-root hypothesis than Zivot and Andrews (1992), but less than Perron (1989). More specifically, they reject at $5 \%$ the null of unit roots for seven of the 13 series analyzed by Nelson and Plosser. Moreover, they reject the unit roots for three of the seven series for which Perron (1989) rejects, but Zivot and Andrews (1992) fail to reject. ${ }^{5}$
5 Other papers that examine macroeconomic time series using the two-break methodology include Ben-David, Lumsdaine and Papell (2003), and Lee and Strazicich (2003). Ultimately, this literature brings about a problem of model selection, in determining the adequate number of breaks in the series. See also Maddala and $\operatorname{Kim}$ (1998). 


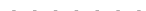

6 A detailed description

of the test procedures developed by LLC and IPS is beyond the scope of this article. See the original references for more details.

\section{4_ Tests for unit roots using panel data}

All tests presented in the previous section are based on single-country data. Recently, attempts have been made in the literature to use panel data in unit root tests (Levin, Lin, and Chu, 2002; Im, Pesaran, and Shin, 2003). In general, the use of panel data is seen as a means of generating more powerful unit root tests. Levin, Lin, and Chu (2002, hereafter LLC) assume that all individuals in the panel have identical first-order partial autocorrelation coefficients, but other parameters such as the degree of persistence in individual regression error, the intercept and trend coefficients are allowed to vary freely across individuals. Their test procedures are designed to assess the null hypothesis, that each individual in the panel has non-stationary time series, versus the alternative hypothesis, that all individuals' time series are stationary. Im, Pesaran, and Shin (2003, hereafter IPS), on the other hand, allow the first order AR coefficient to differ across countries under the alternative hypothesis. ${ }^{6}$

Panel data unit root tests have been used in recent empirical literature on purchasing power parity, and also applied in testing for unit roots in inflation rates, unemployment, and nominal interest rates. Despite the arguments that the use of panel data increases the power of unit root tests, this methodology also has some problems and limitations. First, most panel data tests depend on the assumption that there is no crosssectional correlation among the error terms; an assumption often violated in practice. Second, the results of a panel unit root test are sensitive to the timeseries variables included in the panel.

Culver and Papell (1997) address some of these limitations by performing unit root tests for inflation rate series using sequential break and panel data models. Their findings show that the evidence against the unit-root hypothesis is stronger in panel data tests than in single-country ADF tests.

Finally, Culver and Papell (1997) vary the number of countries in the panel and suggest that the unit-root hypothesis for inflation is very fragile to cross-section variation.

Since the present paper focuses on unit roots tests in GDP series, I will conclude this section by mentioning Rapach (2002), who presents many tests for unit roots in GDP series using panel data for OECD countries. He conducts 
the tests proposed by LLC and IPS, and also uses the seemingly unrelated regressions (SUR) estimator (to handle cross-sectional dependence) and the MADF test (to allow for different firstorder partial autocorrelations under the alternative hypothesis and control for cross-sectional dependence). Rapach (2002) tests for unit roots using the four different methodologies (LLC, IPS, SUR, MADF) in four distinct series:

i. Annual real GDP data, 13 countries, for the period 1956-1996, from the IMF;

ii. Quarterly real GDP data, seven countries, 1965:1 to 1996:4, also from the IMF;

iii. Annual real GDP per capita data, 21 countries, for the period 1950-1992, from the Penn World Tables;

iv. Annual real GDP per capita data, 15 countries, 1900 to 1987, using data derived from Maddison (1989).

For each data set, single-country $\mathrm{ADF}$ tests are also conducted. In this case, the unit root null hypothesis is not rejected for most of the series. The four panel data unit root tests applied by Rapach (2002) seem to confirm the inferences drawn from single-country tests: the null of unit roots is rarely rejected in these tests. Rapach's main conclusion is that

\section{the panel unit root test results reported in the present paper strongly reinforce the view that real output levels are non-stationary (Rapach, 2002, p. 485).}

Finally, Rapach suggests that the results presented should be expanded by allowing for structural breaks in the series along the lines of Perron (1989) and others, since there is evidence that the null of unit roots is more frequently rejected when structural breaks are allowed in the deterministic trend.

\section{3_ Implications for macroeconomic theory and policy}

The traditional procedure of decomposing output fluctuations into a long-run trend and short-run cycles is built upon the assumption that the trend component is a deterministic function of time, and the cyclical component represents a stationary movement around this trend. As is well known, this kind of reasoning cannot be maintained if the trend component is non-stationary, i.e. if the time series features a unit root. In addition, unit roots in GNP series pose 
The main effect can be seen as the advance of real business cycle models and the decline of new classical models - developed by Lucas, Sargent, and Barro, among others, during the 1970s - in which monetary misperceptions were considered the major source of output fluctuations. another challenge for traditional theories of macroeconomic fluctuations, which assume output to be meanreverting and shocks to have only temporary real effects.

In view of these considerations, one of the most important issues in the unit root literature since the work of Nelson and Plosser (1982) is the implications of the presence of unit roots for macroeconomic theory and policy.

\section{1_ Unit roots as a support to real business cycle theory}

At first, evidence of unit roots in GDP time series was used to provide support for theories of fluctuations based on real (as opposed to monetary) factors. This argument is present in the work of Nelson and Plosser (1982), and has strongly influenced the direction of macroeconomic research since the 1980s. 7 Some authors argue that the advance of RBC models - full equilibrium models with emphasis on technology shocks as the source of fluctuations - is mainly due to the empirical findings of Nelson and Plosser (1982). According to McCallum (2000, p. 119), "the logical basis for the upsurge of the RBC movement can be viewed as principally empirical". Or, as stated by Backhouse and Salanti (2000, p. 12),
Although decisive tests are rarely possible, some papers cite one example where such a test occurred: the rejection of the hypothesis that monetary shocks were the cause of the business cycle. This led directly to the emergence of real business cycle theory.

The argument used by Nelson and Plosser (1982) is that most of the fluctuations in output should be attributable to changes in the trend component, in a trend versus cyclical decomposition, which would presumably be unaffected by monetary factors. In other words, the existence of unit roots leads to the inference that movements in output are persistent. Since the cyclical component is assumed to be stationary, it follows that output fluctuations are mostly associated with the secular component. The argument is completed by the idea that monetary shocks are necessarily temporary and so can only affect the cyclical component, and that the long run path of the economy is mainly guided by real factors such as tastes and technology.

Nelson and Plosser's main conclusion in terms of macroeconomic theorizing follows directly from such reasoning, and can be summarized as: 
We conclude that macroeconomic models that focus on monetary disturbances as a source of purely transitory (stationary) fluctuations may never be successful in explaining a very large fraction of output fluctuations and that stochastic variation due to real factors is an essential element of any model of economic fluctuations. (Nelson and Plosser, 1982, p. 141)

It is worthwhile to note that the argument rests on a number of implicit or explicit building blocks, all of which are necessary for the final conclusions. First, Nelson and Plosser use the evidence of unit roots in GNP time series, although they recognize that none of the tests used can distinguish conclusively between a difference stationary process and a trend stationary process with an autoregressive root arbitrarily close to unity.

Second, it is inferred that innovations in the stochastic trend component have a larger variance than the innovations in the transitory component, and this leads to the conclusion that variations in the cyclical component of fluctuations are small in comparison with fluctuations in the trend component. Note that this inference is dependent upon the ability of the empirical analysis to differentiate between a DS and a TS process.
Third, the classical dichotomy between real and monetary variables is assumed. In particular, it is assumed that the cyclical component is stationary, and mainly affected by monetary factors, which are neutral in the long run. ${ }^{8}$ In this respect, Nelson and Plosser acknowledge in a footnote that the theoretical possibility of a "Tobin effect" of sustained inflation on the steady-state capital stock is ignored in their analysis. It is clear that once money is allowed to play any significant role in the long run path of the economy, unit roots do not necessarily support RBC theories (I will return to this point later). In addition, concerning the stationarity of the cyclical component, Nelson and Plosser admit it is a proposition that cannot be inferred from empirical analysis. However, they justify its use by saying that it is an assumption "we believe most economists would accept" (Nelson and Plosser, 1982, p. 160).

The macroeconomic implications of the work of Nelson and Plosser (1982) are controversial, and have not gone uncontested. Many arguments in different directions have been developed in opposition to Nelson and Plosser's findings. ${ }^{9}$ In very general terms, two interrelated lines of criticism can be

\footnotetext{
* * . . . . . . .

8 Indeed, Nelson and Plosser seem to consider a direct and unequivocal association between aggregate demand, monetary factors, and stationary cycles, on one hand, and aggregate supply, real factors, and stochastic trend components, on the other.

9 In this section I will concentrate on the macroeconomic implications of Nelson and Plosser's work. There are also developments concerning other aspects of their analysis, such as the different procedures for testing unit roots discussed in the previous section of this paper.
} 
identified. The first one relates to an effort to reconcile the presence of unit roots in GNP time series with theories of output fluctuations other than RBC models; the other one contests the very existence of unit roots in the series or, more precisely, stresses the inability of unit root tests to differentiate between TS and DS processes in data covering limited time spans.

\subsection{Unit roots and New Keynesian economics}

The first reactions to the conclusions of Nelson and Plosser can be seen as an attempt to promote new Keynesian models of aggregate fluctuations, in which GNP is expected to revert to a long run trend, but in which the adjustment process can be very slow due to imperfections in goods and labor markets. A number of papers were published during the 1980s with different arguments in this direction.

McCallum (1986) claims that the statistical evidence provided by Nelson and Plosser cannot be interpreted as providing support for RBC theory, since this evidence is equally consistent with other theories of the business cycle. His criticism is primarily devoted to the second "building block" mentioned before, $i . e$. that the cyclical component of fluctuations has little importance relative to the secular component.

According to McCallum (1986), this point cannot be inferred from the data presented by Nelson and Plosser (1982), because it depends on the hypothesis that GNP series follows a DS process, which in turn is not guaranteed. McCallum points out and evaluates three types of evidence presented by Nelson and Plosser in favor of the hypothesis of non stationarity. The first piece of evidence is that the sample autocorrelations for annual GNP data are large and decay slowly. The second one is that the autocorrelations of annual GNP differences are positive and significant at lag one, but often not significant at longer lags. McCallum shows that both pieces of evidence are also compatible with the behavior of a trend stationary series with a root close to one, and concludes that it is not possible to determine with any degree of certainty if a series is difference stationary or trend stationary simply by inspection of the autocorrelation functions for levels and differences. The third piece of evidence provided by Nelson and 
Plosser (1982) is formal tests of unit roots. Also in this case, McCallum argues, the evidence is far from conclusive, since unit root tests have low power to distinguish between a DS process and a TS process with an AR root close to unity.

In addition, McCallum (1986) shows that if the decomposition of the series into cyclical and secular components assumes that the latter is given by a DS process, when the process under study is actually one of the TS class with an AR root close to one, then it follows that the variability of the cyclical component will be underestimated. He concludes that

The time series evidence provided by Nelson and Plosser (1982) is inadequate to determine whether the relevant series are of the DS or TS class. This evidence itself, then, sheds little or no light on the issue of the relative variability of cyclical and secular components of typical macroeconomic time series - and consequently provides little or no support for the $\mathrm{RBC}$ bypothesis (McCallum, 1986, p. 407).

The work of Campbell and Mankiw (1987) is also motivated by the findings of Nelson and Plosser (1982). Campbell and Mankiw assert that their goal is to question the view that economic fluctuations can be seen as temporary deviations from a deterministic trend. In view of that, they provide evidence of unit roots in postwar GNP time series, and suggest that persistence of shocks is an important aspect of the data, which "should be used more widely for evaluating theories of economic fluctuations" (Campbell and Mankiw, 1987, p. 858). However, Campbell and Mankiw do not agree with the idea that the existence of unit roots is clear evidence that real, supply-side shocks are the main cause of the business cycle, or that fluctuations based on aggregate demand disturbances should be abandoned.

According to Campbell and Mankiw (1987), traditional theories of economic fluctuations accept two basic premises:

i. fluctuations are mainly caused by aggregate demand shocks;

ii. demand shocks have only short-term effects, and the economy reverts to the natural rate of output in the long run.

They argue that Nelson and Plosser's "extreme" (p. 876) conclusions follow from the abandonment of the first premise. Alternatively, they suggest that 
another way to cope with persistence of shocks is to abandon the second premise, the natural rate hypothesis. This would open the possibility of aggregate demand shocks having persistent effects on output, and this result could be explored in models of multiple equilibria. Campbell and Mankiw conclude:

Perhaps models of temporary nominal rigidities (e. g., Fischer [1977]) or misperceptions (e. g., Lucas [1973]) could be reconciled with findings of persistence by abandoning the natural rate hypothesis in favor of some highly potent propagation mechanism (Campbell and Mankiw, 1987, p. 877).

In sum, Campbell and Mankiw seem to provide a response to the work of Nelson and Plosser (1982). In other words, they point to the validity of some of the main aspects of "traditional theories of the business cycle" despite the findings of Nelson and Plosser. However, it is not clear how models such as Lucas (1973) and Fischer (1977) could stand without the natural rate hypothesis, and Campbell and Mankiw do not present any other suggestions in this direction. Possibly, some sort of equilibrium rate of output would need to be assumed in the long run, even if the process of return to trend is assumed to be very slow due to rigidities and other forms of imperfections (like in many models in the new Keynesian literature).

West (1988) offers an answer to this issue, contesting the evidence of unit roots in GNP time series, as well as the need to abandon the idea of a natural rate of output. West's argument has two parts. The first part is the well known fact that unit root tests cannot discriminate between random walk and near random walk behavior in finite samples. This implies, according to West (1988) that simple analysis of a single-country GNP data series is not sufficient to distinguish between stationarity and non stationarity, and to evaluate the relative importance of nominal and real shocks; therefore, this type of empirical evidence is not sufficient to assert the usefulness of different theories of the business cycle.

The second part of West's argument consists in showing that simple natural rate models in which nominal shocks are the main cause of fluctuations can generate results similar to a near random walk in GDP. In short, West (1988) builds a simple model with overlapping wage contracts 
in which monetary policy is the only source of disturbances. Intuitively, the wage contracts provide an endogenous source of persistence, since prices do not move instantaneously, and GNP fluctuations mimic a near random walk behavior after a monetary policy shock. This is valid even if there is a long run natural rate of output to which the economy eventually converges; all that is needed for near random walk behavior is a very slow process of adjustment. In sum, West's main point is that

Neither stationarity of the natural rate nor nominal shocks playing an important role in the business cycle are inconsistent with a root very near to unity being present in the GNP process (West, 1988, p. 207, emphasis added)

It is clear that West minimizes the importance of unit roots in GNP series, based on the fact that random walk and near random walk behavior cannot be distinguished. However, if the actual process behind GNP series is difference stationary (although one cannot be sure of it), the concept of the natural rate of unemployment is called into question. Moreover, if the idea of near random walk is a valid description of the behavior of GNP or, in other words, if GNP is trend reverting but with a high degree of persistence, it seems that the concept of a unique and stable natural rate is not very useful anyway. ${ }^{10}$ The target is still there, but the economy never reaches it, and successive shocks may drive economic fluctuations independently of what the natural rate is, since its attraction power is very low.

\section{3 "We don't know, and we don't care", and other arguments}

Another line of argumentation in the unit roots debate claims that it is not really important for macroeconomic theorizing whether or not unit roots are detected in GNP time series. This branch of the literature has a lot in common with some arguments presented in the previous section, especially those by McCallum (1986) and West (1988), about the inability of unit root tests to distinguish between TS and DS processes in finite samples. In this case, however, the criticism seems to be even more profound; moreover, there is not a defense of any specific theories of economic fluctuations.

The original contribution to the "we don't know" literature is the work of Christiano and Eichenbaum (1990). Their basic proposition is that it is not possible to provide a compelling case
${ }^{10}$ For a broad discussion of the concept of the natural rate of unemployment, see Cross (1995). 
that real GNP is either trend or difference stationary based on the analysis of postwar data.

According to Christiano and Eichenbaum (1990), the main difference between the two models can be analyzed by looking at how much an innovation to real GNP affects the forecast of this variable into the infinite future. They try to answer this question by using the two measures of persistence discussed before: the ones by Campbell and Mankiw (1987) and Cochrane (1988).

Christiano and Eichenbaum (1990) estimate different ARMA specifications for real GNP, in order to analyze the impulse response functions proposed by Campbell and Mankiw. They show that for the postwar US data, the relative plausibility of the trend and the difference stationary representations depends critically on the precise order of the ARMA specification chosen: under an ARMA $(2,2)$ representation, for instance, GNP can be seen as difference stationary; under an ARMA $(3,3)$ specification, however, GNP can be seen as trend stationary. According to Christiano and Eichenbaum, neither economic theory nor the data can conclusively distinguish between the two competing representations.
The nonparametric measure of persistence proposed by Cochrane (1988) is also applied to the US data. In this case, Christiano and Eichenbaum (1990) argue that the variance ratio statistic is also not able to provide conclusive information about whether GNP is a TS or DS process. They show that the estimations based on postwar data are consistent with the view that GNP is more persistent than a random walk, but are also consistent with the view that GNP is less persistent than a random walk. Once more, one is not able to tell which is true.

Finally, Christiano and Eichenbaum (1990) explore the implications of unit roots in two different contexts: the permanent income hypothesis, and real business cycle models. They argue that the implications of the presence of unit roots for these models are minimal. Their conclusion is quite skeptical:

We think macroeconomists should care
very much about the relative importance
of permanent and temporary shocks to
agents' environments. But conventional
atheoretical measures of persistence
convey little information about this
question, and structural inferences
based on such measures ought to be
viewed with extreme skepticism
(Christiano and Eichenbaum, 1990, p. 54). 
Other examples of the "we don't know, and we don't care" literature are Rudebusch (1992), Diebold and Rudebusch (1999), and Smith (2000). Rudebusch (1992) calls for a new consensus that would emphasize the difficulties of "knowing anything" about the existence of unit roots in macroeconomic time series. Besides, he points out that the tests performed by Nelson and Plosser (1982) have low power not against TS models with an AR root close to unity but, more importantly, against plausible TS models estimated from the data.

Diebold and Rudebusch (1999) emphasize that there is a great deal of uncertainty regarding the nature of the trend in macroeconomic time series, the estimation of persistence to shocks, and the decomposition of trend and cycle.

Finally, Smith (2000) makes a more general criticism of the attempts to draw conclusions about the behavior of macroeconomic variables from the existence or not of unit roots in the series. ${ }^{11}$ He stresses that unit root tests are very sensitive to a number of variables, such as the sample used, the number of lags, the inclusion of intercept and trend parameters, and the existence of structural breaks; he argues that such sensitivity helps to explain why there is no consensus about whether macroeconomic variables are stationary or not, even for widely studied series, such as the US GNP. Moreover, Smith (2000) argues that statistical techniques cannot generally give precise answers to questions of economic interest, and that these answers involve interpretation. $\mathrm{He}$ criticizes the unit root literature by saying that

\section{much of the problem with the unit root literature arises from the belief that estimates or test statistics would provide the answer in themselves (Smith, 2000, p. 200-201).}

\section{4_Unit roots and non-mainstream perspectives in macroeconomics}

The existence of unit roots in GDP time series and the consequent persistence of shocks can also be used to support different non-mainstream views of economic fluctuations and economic growth, which emphasize the existence of multiple equilibria with the possibility of persistent involuntary unemployment, due to path dependence, hysteresis in labor markets, and non-neutrality of money in the long run, among other considerations.

Dutt and Ros (2003) present a broad review of models in which

\footnotetext{
$\ldots \ldots \ldots$ 11 Strictly speaking, Smith (2000) needs not necessarily to be included in the "we don't know" literature, since his arguments do not fit exactly in that category, although there are some elements in common.
} 
aggregate demand contractions have long term effects on output. Their main goal is to criticize the so-called "spring theory" of stabilization and growth, which is implicit in the recommendations of the IMF and other international financial institutions for economies dealing with financial and currency crises, and can be summarized as:

Following an initial contraction, the economy will be able to spring back to a normal full employment path that is independent of the size of the contraction itself. Even more, the economy may well be able to spring back faster, the greater the magnitude of the contraction (Dutt and Ros, 2003, p. 2).

Dutt and Ros (2003) explore a variety of mechanisms in which automatic tendencies of adjustment to a "normal" path are absent or weak, leading to persistent effects of shocks in output. There are, generally speaking, two subgroups of models. First, Dutt and Ros (2003) analyze models in which the trend-reverting tendencies of the economy are weakened by some sort of path dependence, which change the long run position of the economy itself. This includes the effects of hysteresis in labor markets, the existence of multiple equilibria associated with increasing returns to scale, and the effects of currency overvaluation in open economies with balance of payment constraints.

The second group of models presented by Dutt and Ros (2003) explore situations in which automatic adjustment tendencies are absent or offset, even if "frictions" or "rigidities" are removed from the economy. The reasons for non-convergence relate to:

i. regressive income redistribution due to changes in money and prices, and consequent effects on the propensity to consume;

ii. negative effects of deflation on investment, due to increase in the real value of firms' debts; iii. changes in expectations due to falling prices and wages, which can paralyze consumption or investment decisions in case of pervasive uncertainty;

iv. liquidity trap, which prevents further reduction in the interest rate, and therefore prevents recovery of investments;

$\mathrm{v}$. endogeneity of money.

It is clear that in all these situations, when subject to a negative shock, the economy is unable to return promptly to its previous trajectory. In 
some cases, the very concept of a unique long-term trend of output is abandoned. All these results are compatible with the existence of unit roots in output series, or with the idea that output follows a random walk, with no tendency to return to any predetermined mean.

In general terms, it can be argued that many theories in which aggregate demand influences the long run equilibrium of the economy, or in which the concept of a natural rate of unemployment (unique and stable) is discarded, are compatible with the presence of unit roots in GNP. Examples include the type of models developed by Hahn and Solow (1995), 12 structuralist models a la Taylor (1991), and the "fundamentalist" branch of post Keynesianism (Davidson, Minsky, among others). The existence or not of unit roots, however, has not been discussed in this literature, and a more detailed evaluation of these possible links is beyond the scope of this paper.

\section{4_Empirical evidence of unit roots for Latin American countries}

The previous section has shown that the implications of unit roots for macroeconomic theory and policy are controversial, and have been subject to conflicting interpretations. Empirical evidence, on the other hand, has not been able to resolve the dispute over whether or not unit roots are important to explain output fluctuations.

The empirical literature on the existence of unit roots in GNP time series is enormous but concentrates mainly on developed countries, with the US coming at the top of the rank.

More recently, however, a growing number of studies is addressing the issue of unit roots in developing economies. In this section, I will review the results of unit root tests applied to Latin American economies, with emphasis on four countries: Argentina, Brazil, Chile, and Mexico. In general, the results of these studies show the same difficulties and dilemmas discussed in the previous sections.

Thornton (2001) studies the relation between population growth and real GDP per capita growth in the long run for seven Latin American countries. He uses three different techniques, namely, ADF tests, the Johansen maximal likelihood procedure, and Granger causality tests, to evaluate the relation between population and per capita income in Argentina, Brazil,
12 Note, however, that the work of Hahn and Solow (1995) cannot be classified as non-mainstream macroeconomics. Even so, they consider models in which aggregate demand influences the long-run path of the system, and in which there is no unique and stable natural rate of unemployment. I would like to thank an anonymous referee for his suggestion about this point. 
Chile, Colombia, Mexico, Peru, and Venezuela over the 1900-1994 period.

Concerning unit root tests, Thornton (2001) performs ADF tests for levels and first differences of GDP per capita, with intercept and no trend, and also with both intercept and trend. $\mathrm{He}$ is unable to reject the null of unit roots in per capita GDP levels for any of the countries and specifications, whereas the null is always rejected in case of first differences. Thornton (2001) concludes that per capita income in these countries is a $\mathrm{I}(1)$ variable, i. e., non-stationary.

The presence of unit roots in Argentinean GDP series is analyzed by Sosa-Escudero (1997), Carrera, Feliz and Panigo (1999) and Utrera (undated).

Sosa-Escudero (1997) presents the first attempt to test for unit roots in the case of Argentina. He uses annual real GDP data for the 1900-1993 period, and quarterly real GDP data from 1970:1 to 1994:2. Sosa-Escudero (1997) applies ADF and Phillips-Perron tests allowing for structural breaks. In particular, he uses the methodology proposed by Banerjee et al. (1992) recursive tests, rolling tests and sequential tests - in which the date of the break is endogenously determined. The results provided in all tests for both annual and quarterly data show that the null of unit root cannot be rejected at a $10 \%$ level of significance. Sosa-Escudero (1997) concludes by suggesting that real GDP in Argentina appears to be non-stationary and, as a consequence, suffers persistent effects from shocks.

Carrera, Feliz and Panigo (1999) expand this study in two directions. First, they analyze a large number of macroeconomic variables (fourteen series), including GDP, wages, interest rates, unemployment rates, exchange rates, and inflation. Second, they perform various tests to evaluate the persistence of shocks in the economy. Their analysis use quarterly data for the period 1980:1 to 1998:4, and comprises:

i. the examination of first order autocorrelation coefficients;

ii. ADF and PP unit root tests with no breaks;

iii. Cochrane's (1988) variance ratio statistic;

iv. unit root tests with exogenous breaks (Perron, 1989); and recursive and rolling ADF tests for unit roots (Banerjee et al, 1992).

Considering the order of integration of GDP, Carrera, Feliz, and Panigo (1999) show that they consider it as "robustly" 
I(1), confirming the unit root hypothesis. This is because GDP series appear to be non-stationary in all the tests applied, even when allowance is made for structural breaks. This result is compatible with the inferences provided by Sosa-Escudero (1997).

Finally, Utrera (undated) provides the third study for the case of Argentina. In his paper, however, the evidence suggests the opposite result of the previous two studies. Utrera uses resampling techniques proposed by Rudebusch (1992), in order to obtain the small sample distributions of the $t$ statistic used to test the null of unit root conditional on both the DS null and the TS alternative hypothesis. This technique permits the analysis of the size of the unit root test, as well as its power to reject false nulls, and allows for multiple endogenous structural breaks. The tests are applied to annual GDP and GDP per capita data for the 1913-1999 period and to quarterly GDP data for the 1970:1-2000.3period. The results, in general, support the idea that Argentinean GDP is stationary around a broken trend:

i. with no breaks, neither the

DS nor the TS hypotheses can be rejected; ii. with one, two, or three endogenous structural breaks the DS null tends to be rejected, whereas the alternative TS hypothesis is not rejected.

Utrera (undated) concludes that GDP in Argentina is better described as a stationary variable. ${ }^{13}$

In the case of Brazil, pioneering studies were done by Cribari Neto (1990, 1992). In the first paper, Cribari Neto (1990) analyzes the persistence of innovations in Brazilian GDP using annual data for the 1950-1985 period. Three different methodologies are used: ADF tests, impulse response functions (Campbell and Mankiw, 1987), and Cochrane's (1988) variance ratio.

The results suggest that the unit roots hypothesis cannot be rejected, and that Brazilian GNP is more persistent than a random walk (a 1\% shock will have an effect greater than 1\% in the long run). In the second paper, Cribari Neto (1992) expands the sample for the 1900-1985 period and, using the same methodology, confirms the results of his 1990 study.

Tombini and Newbold (1992) analyze the behavior of Brazilian GDP for the years 1947-1987. They develop a model with three structural breaks
-

13 It is interesting to note that the case for stationarity becomes stronger when a larger number of breaks is included. This result is expected, given the analysis of Perron (1989), and it is also intuitive, since any series can be decomposed into stationary segments if one allows for a sufficiently large number of breaks. 
("interventions") during this period, by incorporating dummy variables into the time series a la Perron (1989).

The breaks are:

i. the political turbulences and economic reforms in 1962;

ii. the first oil shock in 1973;

iii. the second oil shock in 1979.

Tombini and Newbold (1992) intend to estimate the impact of these shocks in the behavior of GDP over time. Although the paper does not provide formal tests of unit roots, the results provide support to the hypothesis of a stationary variation around a broken trend.

Aguirre and Ferreira (2001) provide the most recent study of unit roots in Brazilian GDP. They use annual data for the 1950-1997 period and perform three different tests: ADF test with no breaks, KPSS tests (in which TS is the null hypothesis), and ADF tests with endogenous breaks. In the first case, the ADF test suggests the existence of a unit root in the series. This result is confirmed by the KPSS test, since the null of stationarity is rejected at 5\%. However, when allowance is made for an endogenous break (change in slope in 1979), the opposite result is obtained, and the null of unit roots is rejected. Aguirre and Ferreira
(2001) conclude that Brazilian GDP is stationary around a broken trend.

Chumacero (2000) presents various unit-root tests for Chile. He uses annual and quarterly data ${ }^{14}$ to perform ADF tests, PP tests, KPSS tests, tests with endogenous breaks based on Zivot and Andrews (1992), and ADF tests with non linear trends. The evidence based on these tests is not conclusive; in some cases the unit root hypothesis is rejected, and in other cases it is not. Chumacero (2000) also proposes an indirect test of unit roots "based on economic theory", in which he uses a representative-agent model that maximizes utility over time. In this case, the results suggest that the null of unit root is rejected. Chumacero (2000) concludes that GDP for the Chilean economy appears to be stationary.

The presence of unit roots in Mexican GDP is discussed by Carstens and Reynoso (1997), Moreno-Brid (1999), Noriega and Ramirez-Zamora (1999), and Castillo Ponce and Diaz Bautista (2002). Carstens and Reynoso (1997) analyze the effects of monetary policy on the Mexican economy. Among other goals, they try to assess the relation between money stock and GDP using cointegration techniques. In order to check for the order of
14 The period of analysis is not specified in the paper. 
integration of the variables, $\mathrm{ADF}$ and PP unit root tests are performed, with different specifications for trends and intercepts. In the case of real GDP, the results suggest the existence of unit roots in the series, and Carstens and Reynoso (1997) conclude that Mexican GDP is integrated of order one.

Moreno-Brid (1999) uses unit root tests and cointegration analysis to estimate the long-run relation between export growth and GDP growth in Mexico (1950-1996). His analysis is based on the balance-of-payments constraints model developed by Thirlwall. Moreno-Brid (1999) performs $\mathrm{ADF}$ tests and finds results that suggest that real GDP is a I(1), or difference stationary, variable.

The paper by Noriega and Ramirez-Zamora (1999) presents many similarities with the work of Utrera (undated) mentioned before. Noriega and Ramirez-Zamora (1999) use resampling techniques (Rudebusch, 1992) to check for the existence of unit roots in Mexican GDP (1921-1995) and GDP per capita (1921-1994). This technique allows for multiple structural breaks determined endogenously, and compares the plausibility of DS and TS alternatives. The results shown by
Noriega and Ramirez-Zamora (1999) are similar for both variables analyzed, and can be summarized as the following:

i. in case of no breaks, it is not possible to discriminate between the DS and the TS specifications; ii. in case of one, two, or three breaks, the unit root hypothesis is rejected in favor of a TS specification.

Noriega and Ramirez-Zamora (1999, p. 182) conclude that

Mexico's real output has fluctuated stationarily around a 75 year long-run trend perturbed by three major events in or around 1931, 1950, and 1980.

Castillo Ponce and Diaz Bautista (2002) analyze the stochastic behavior of Mexican GDP using annual data for the 1900-2001 period. They use different methodologies, that include the examination of autocorrelation coefficients, ADF and PP tests with no breaks, tests with exogenous breaks (Perron, 1989), and tests with endogenous breaks (Zivot and Andrews, 1992). In accordance with most of the literature on unit roots, Castillo Ponce and Diaz Bautista (2002) find that GNP is non stationary when tests with no breaks are performed. 
An interesting feature of their results, however, is that the hypothesis of non stationarity is robust to the inclusion of breaks. That is, when exogenous breaks (in 1932, 1983, and 1995) or endogenous breaks (in 1907) are allowed, the null of unit roots is not rejected in the tests. Castillo Ponce and Diaz Bautista (2002) conclude that Mexican GDP is non stationary.

In sum, a quick review of the literature of unit roots in Latin American countries shows no conclusive result, which is also consistent with the literature on developed countries. Given the low power of unit root tests, and the sensibility of its results to a number of influences, the fact that the evidence presented is not decisive does not come as a surprise. There seem to be, however, a general tendency not to reject the null hypothesis of unit roots, and to consider GNP to be integrated of order one. On the other hand, when allowance is made for structural breaks, there is evidence that the null of unit roots is rejected more often, although not in all cases. This is also not a surprise, given the work of Perron (1989).

\section{5_ Final remarks}

As discussed in the previous sections, the issue of unit roots in macroeconomic time series has motivated a vast amount of theoretical and empirical research in the past two decades. It is interesting to point out, however, that a consensual view on many of the aspects involved has not emerged from this literature. There seem to be no consensus about the most appropriate methodologies to perform unit root tests; no consensus about the theoretical importance of the concept of unit roots and its implications for macroeconomic analysis; and no consensus about empirical results of unit root tests for many countries.

This paper intended to explore some of these controversies, assessing some aspects of the unit root literature in econometrics and macroeconomics. Finally, the article presented the recent empirical evidence on unit roots for Latin American economies.

I conclude by mentioning two points. The first one concerns the implications of the existence of unit roots for macroeconomic policies. Since the existence and importance of unit roots in macroeconomic series is a very controversial issue, and the literature 
seems to have reached no consensus on many crucial aspects of the debate, it should be clear from the beginning that no strong and conclusive policy recommendations can be derived here. However, if there is a unit root in GNP, it suggests that automatic return to a normal trend may not occur, and therefore full employment policies may have a role to perform. On the other hand, it is also possible to make a case against sharp contractions as a response to financial or currency crises (Dutt and Ros, 2003), since the negative effects of such policies do not tend to dissipate in the short run.

The second point concerns issues not addressed in this paper, or suggestions for future directions of research. In short, at least four issues could be mentioned:

i. more detailed analysis of the implications for macroeconomic policies (fiscal, monetary, exchange rate policies) in the presence of unit roots;

ii. an investigation of the possible relation between the unit roots literature and non mainstream perspectives in macroeconomics (post Keynesian, structuralist, etc.); iii. methodologies to perform panel data tests of unit roots allowing for structural breaks, as suggested by Rappach (2002);

iv. extensi on of the analysis of unit roots for developing countries in general, and Latin American countries in particular. 


\section{References}

AGUIRRE, A.; FERREIRA, A The (in)existence of a unit root in brazilian gross domestic product. Applied Economic Letters, v. 8, p. 645-647, 2001.

BACKHOUSE, R.; SALANTI, A. Macroeconomics and the real world. New York: Oxford University Press, 2000. (v. 1: Econometric techniques and macroeconomics).

BANERJEE, A.; LUMSDAINE, R.; STOCK, J. Recursive and sequential tests of the unit-root and trend-break hypotheses: theory and international evidence. Journal of Business and Economic Statistics, v. 10, n. 3, p. 271-287, July, 1992.

BEN-DAVID, D.; LUMSDAINE, R.; PAPELL, D. Unit roots, postwar slowdowns and long-run growth: evidence from two structural breaks. Empirical Economics, v. 28, n. 2, p. 303-319, 2003.

BLANCHARD, O.; QUAH, D. The dynamic effects of aggregate demand and supply disturbances. American Economic Review, v. 79, n. 4, p. 655-673, September 1989. CAMPBELL, J.; MANKIW, G. International evidence of the persistence of economic fluctuations, Journal of Monetary Economics, v. 23, p. 319-333, 1989.
CAMPBELL, J.; MANKIW, G. Are output fluctuations transitory? Quarterly Journal of Economics, v. 102, p. 857-880, 1987.

CARRERA, J.; FELIZ, M.; PANIGO, D. Unit roots and cycles in the main macroeconomic variables for Argentina. XXXIV Reunión Anual de la Asociación Argentina de Economía Política, 1999.

CARSTENS, A.; REYNOSO, A. Alcances de la politica monetaria: marco teorico y regularidades empiricas en la experiencia mexicana. Banco de Mexico, 1997. (Documento de Investigación 9705). 45p.

CASTILLO PONCE, R.; DÍAZ-BAUTISTA, A. Testing for unit roots: Mexico's GDP. Momento Económico, v. 124, n. 2-10, 2002.

CHRISTIANO, L.; EICHENBAUM, M. Unit roots in real GDP: do we know, and do we care? Carnegie Rochester Conference Series on Public Policy, v. 32, p. 7-62, 1990.

CHUMACERO, R. Se busca una raiz unitaria: evidencia para Chile. Estudios de Economía, v. 27, n. 1, p. $55-68,2000$.
COCHRANE, J. How big is random walk in GDP?. Journal of Political Economy, v. 96, n. 5, p. 893-92, 1988.

CRIBARI NETO, F. On time series econometrics. Quarterly Review of Economics and Finance, v. 36, special issue: p. 37-60, 1996.

CRIBARI NETO, F. Persistência de inovações e política econômica: a experiência do II PND. Revista Brasileira de Economia, v. 46, n. 3, p. 413-428, 1992.

\section{CRIBARI NETO, F. O}

comportamento estocástico do produto no Brasil. Pesquisa e Planejamento Econômico, v. 20, n. 2, p. 381-402, 1990.

CROSS, $\mathrm{R}$. The natural rate of unemployment: reflections on 25 years of the hypothesis. Cambridge: Cambridge University Press, 1995.

CULVER, S.; PAPELL, D. Is there a unit root in the inflation rate? Evidence from sequential break and panel data models. Journal of Applied Econometrics, v. 12, p. 435-444, 1997.
DICKEY, D.; FULLER, W.

Distribution of the estimators for autoregressive time series with a unit root. Journal of the American Statistical Association, v. 74, p. 427-431, 1979 .

DIEBOLD, F.; RUDEBUSCH,

G. Business cycles. Princeton: Princeton University Press, 1999. DUTT, A.; ROS, J.

Contractionary effects of stabilization and long run growth. University of Notre Dame, 2003. Unpublished manuscript.

ELDER, J.; KENNEDY, P. Testing for unit roots: what should students be taught? Journal of Economic Education, p. 137-146, Spring 2001.

ENDERS, W. Applied econometric time series. New York: Wiley, 1995.

FISCHER, S. Long-term contracts, rational expectations, and the optimal money supply rule. Journal of Political Economy, v. 85 , n. 1, p. 191-205, 1977.

HAHN, F.; SOLOW, R. A critical essay on modern macroeconomic theory. Cambridge, MA: MIT Press, 1995. 
IM, KYUNG SO; PESARAN, M. HASHEM; SHIN,

YONGCHEOL. Testing for unit roots in heterogeneous panels. Journal of Econometrics, v. 115, n. 1, p. 53-74, 2003.

\section{KWIATKOWSKI, D.;} PHILLIPS, P.; SCHMIDT, P.; SHIN, Y. Testing the null hypothesis of stationarity against the alternative of a unit root: how sure are we that economic time series have a unit root? Journal of Econometrics, v. 54, p. 159-178, 1992.

\section{LEE, J.; STRAZICICH, M.}

Minimum lagrange multiplier unit root test with two structural breaks. Review of Economics and Statistics, v. 85 , n. 4, p. 1082-1089, 2003.

\section{LEVIN, A.; LIN, C.; CHU, C.} Unit root tests in panel data: asymptotic and finite-sample properties. Journal of Econometrics, v. 108, n. 1, p. 1-24, 2002.

LUCAS, R. Some international evidence on output-inflation trade-offs. American

Economic Review, v. 63, n. 3, p. 326-334, 1973.

\section{LUMSDAINE, R.; PAPELL, D.}

Multiple trend breaks and the unit-root hypothesis. Review of Economics and Statistics, v. 79 p. 212-218, 1997.

MADDALA, G. S.; KIM, I. Unit roots, cointegration, and structural change. Cambridge: Cambridge University Press, 1998.

MADDISON, A. The World Economy in the 20th Century. Paris: OECD, 1989.
MCCALLUM, B. Recent

developments in monetary policy analysis: the roles of theory and evidence. In: BACKHOUSE, R.; SALANTI, A. Macroeconomics and the Real World. New York: Oxford University Press, 2000. p. 115-139.

MCCALLUM, B. On 'real' and 'sticky-price' theories of the business cycle. Journal of Money, Credit, and Banking, v. 18, n. 4 , p. 397-414, November 1986.

MORENO-BRID, J. Mexico's economic growth and the balance of payments constraint: a cointegration analysis. International Review of Applied Economics, v. 13, n. 2, p. 149-159, 1999.

NELSON, C.; PLOSSER, C. Trends and random walks in macroeconomic time series: some evidence and implications. Journal of Monetary Economics, v. 10, p. 139-169, 1982.

\section{NORIEGA, A.,} RAMIREZ-ZAMORA, A. Unit roots and multiple structural breaks in real output: how long does an economy remain stationary? Estudios Económicos, v. 14, n. 2, p. 163-188, 1999.

PERRON, P. The great crash, the oil price shock, and the unit root hypothesis. Econometrica, v. 57, p. 1361-1401, 1989.

RAPACH, D. Are real GDP levels nonstationary? Evidence from panel data tests. Southern Economic Journal, v. 68, n. 3, p. 473-495, 2002.
RUDEBUSCH, G. Trends and random walks in macroeconomic time series: a reexamination. International Economic Review, v. 33, p. 661-680, 1992.

SMITH, R. Unit roots and all that: the impact of time-series methods on macroeconomics. In: BACKHOUSE, R.; SALANTI, A. Macroeconomics and the Real World. New York: Oxford University Press, 2000. p. 199-218.

SOSA-ESCUDERO, W. Testing for unit-roots and trend-breaks in Argentine real GDP. Económica, v. 43, p. 123-142, 1997.

TAYLOR, L. Income distribution, inflation and growtb: lectures on structuralist macroeconomic theory. Cambridge, Mass.: MIT Press, 1991.

TOMBINI, A.; NEWBOLD, P. The time-series behavior of brazilian real gross domestic product, 1947-87: an analysis of interventions. World Development, v. 20, n. 2, p. 283-288, 1992.

THORNTON, J. Population growth and economic growth: long-run evidence from Latin America. Southern Economic Journal, v. 68 , n. 2 , p. 464-468, 2001.

UTRERA, G. Is the Argentine GDP stationary around a broken trend? [s. d.]. unpublished manuscript.

WEST, $\mathrm{K}$. On the interpretation of near random-walk behavior in GDP. American Economic Review, v. 78, n. 1, p. 202-209, March 1988.
ZIVOT, E.; ANDREWS, D. Further evidence on the great crash, the oil-price shock, and the unit-root hypothesis. Journal of Business \& Economic Statistics, v. 10, n. 3, p. 251-270, 1992.

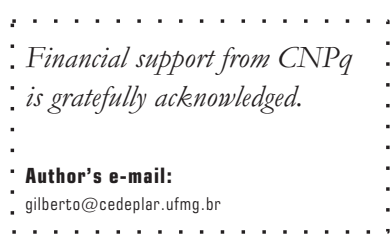

